\title{
Centralized Self-Healing Scheme for Electrical Distribution Systems
}

\author{
Patricia L. Cavalcante, Juan Camilo López, John F. Franco, Member, IEEE, Marcos J. Rider, Member, IEEE, \\ Ariovaldo V. Garcia, Marcos R. R. Malveira, Luana L. Martins, and Luiz Carlos M. Direito
}

\begin{abstract}
In this paper, a two-stage procedure is proposed in order to solve the centralized self-healing scheme for electrical distribution systems. The considered self-healing actions are the reconfiguration of the distribution grid and, if needed, node and zone load-shedding. Thus, the proposed procedure determines the status of the switching devices in order to effectively isolate a faulty zone and minimize the number of de-energized nodes and zones, while ensuring that the operative and electrical constraints of the system are not violated. The proposed method is comprised of two stages. The first stage solves a mixed integer linear programming (MILP) problem in order to obtain the binary decision variables for the self-healing scheme (i.e., the switching device status and energized zones). In the second stage, a nonlinear programming (NLP) problem is solved in order to adjust the steady-state operating point of the topology found in the first stage (i.e., correction of the continuous electrical variables and load-shedding optimization). Commercial optimization solvers are used in the first stage to solve the MILP problem and in the second stage to solve the NLP problem. A 44-node test system and a real Brazilian distribution system with 964-nodes were used to test and verify the proposed methodology.
\end{abstract}

Index Terms-Centralized self-healing scheme, load-shedding, mixed integer nonlinear programming, service restoration.

\section{NOMENCLATURE}

The notation used throughout this paper is reproduced below for reference.

Sets

$\Omega_{b} \quad$ Set of nodes.

Manuscript received August 8, 2014; revised January 23, 2015 and April 15, 2015; accepted July 6, 2015. Date of publication August 3, 2015; date of current version December 19, 2015. This work was supported in part by the Brazilian Institution Coordenação de Aperfeiçoamento de Pessoal de Nível Superior, in part by Conselho Nacional de Desenvolvimento Científico e Tecnológico, and in part by Pesquisa e Desenvolvimento da Agẽncia Nacional de Energia Elétrica. Paper no. TSG-00794-2014.

P. L. Cavalcante, M. R. R. Malveira, and L. L. Martins are with the Centro de Pesquisa e Desenvolvimento em Telecomunicações, Campinas 13086-902, Brazil (e-mail: plopes@cpqd.com.br; malveira@cpqd.com.br; luana@cpqd.com.br).

J. C. López and M. J. Rider are with the Department of Systems and Energy, University of Campinas, Campinas 13083-852, Brazil (e-mail: amezquitaunal@gmail.com; mjrider@dsee.fee.unicamp.br).

J. F. Franco is with the Departamento de Engenheria Elétrica, Facultade de Engenheria de Ilha Solteira-Universidade Estadual Paulista, Ilha Solteira 15385-000, Brazil (e-mail: jffranco@gmail.com).

A. V. Garcia is with the A V Garcia Tecnologia de Informação, Campinas 13085-415, Brazil (e-mail: garcia.av@gmail.com).

L. C. M. Direito is with the Light Serviços de Eletricidade, Rio de Janeiro 3326-9122, Brazil (e-mail: luiz.direito@light.com.br).

Color versions of one or more of the figures in this paper are available online at http://ieeexplore.ieee.org.

Digital Object Identifier 10.1109/TSG.2015.2454436

$\begin{array}{ll}\Omega_{b}^{s} & \text { Set of source nodes. } \\ \Omega_{l} & \text { Set of branches. } \\ \Omega_{\mathrm{SW}} & \text { Set of switches. } \\ \Omega_{z} & \text { Set of load zones. }\end{array}$

\section{Functions}

$f(y, \bar{y}, \Lambda)$ Piecewise linear approximation of the square value of $y$.

\section{Parameters}

$\Lambda \quad$ Number of discretizations used in function $f$.

$\phi_{y, \lambda} \quad$ Value of the $\lambda$ th slope used in the discretization of $y$.

$c_{z}^{R} \quad$ Cost of de-energizing zone $z \in \Omega_{z}[\mathrm{US} \$ / \mathrm{kW}$.

$c_{i}^{\mathrm{ls}} \quad$ Cost of load-shedding at node $i \in \Omega_{b}$ [US $\$ / \mathrm{kW}$.

$c^{\text {lss }} \quad$ Cost of active power losses [US $\$ / \mathrm{kW}$ ].

$c^{\mathrm{sw}} \quad$ Cost of switch operation [US\$].

$\bar{I}_{i j}$

Maximum current magnitude through branch ij [A].

$\bar{I}_{i j}^{\mathrm{sw}} \quad$ Maximum current magnitude through switch $i j$ [A].

$P_{i}^{D} \quad$ Active power demand at node $i[\mathrm{~kW}]$.

$Q_{i}^{D}$

$R_{i j}$

Reactive power demand at node $i$ [kVAr].

Resistance of branch $i j[\mathrm{~m} \Omega]$.

$\bar{r}_{i} \quad$ Maximum percentage of load-shedding allowed at node $i[\%]$.

$\bar{S}_{i} \quad$ Maximum apparent power generated at node $i$ [kVA].

$s_{i j}^{\text {ini }} \quad$ Initial state of switch $i j$, where $s_{i j}^{\text {ini }}=1$ if switch $i j$ is initially closed, or $s_{i j}^{\text {ini }}=0$, otherwise.

$\bar{V} \quad$ Maximum voltage magnitude [kV].

$\underline{V} \quad$ Minimum voltage magnitude $[\mathrm{kV}]$.

$\bar{V}^{\text {nom }} \quad$ Nominal voltage magnitude $[\mathrm{kV}]$.

$X_{i j} \quad$ Reactance of branch $i j[\mathrm{~m} \Omega]$.

$\bar{y} \quad$ Maximum value of $y$.

$Z_{i j} \quad$ Impedance of branch $i j[\mathrm{~m} \Omega]$.

$z_{i}^{b} \quad$ Zone of node $i$.

$z_{i j}^{l} \quad$ Zone of branch $i j$.

\section{Continuous Variables}

$\Delta_{y, \lambda} \quad$ Value of the $\lambda$ th auxiliary variable used in the discretization of $y$.

$I_{i j} \quad$ Current magnitude through branch $i j[\mathrm{~A}]$.

$I_{i j}^{\text {sqr }} \quad$ Square of $I_{i j}$. 


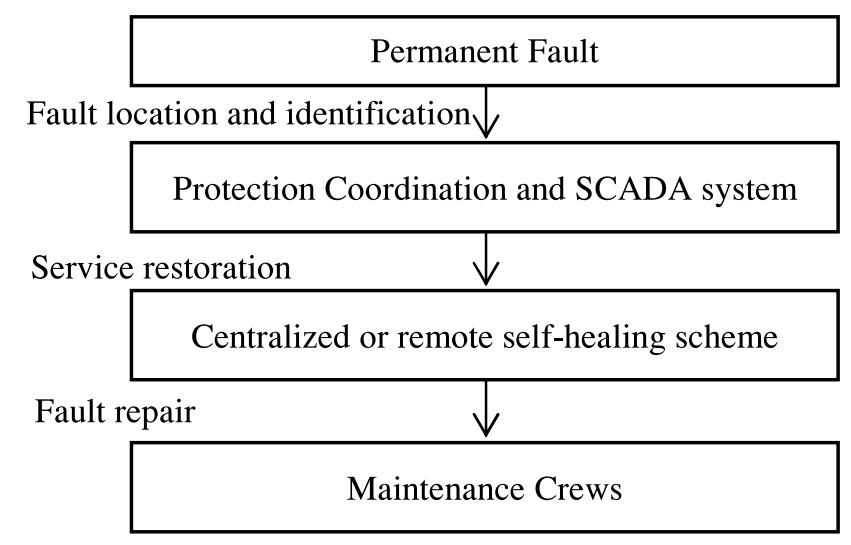

Fig. 1. Sequence of technologies used for the location, identification, and restoration of faults in modern distribution systems.

$\begin{array}{ll}I_{i j}^{\mathrm{sw}} & \text { Current magnitude through switch } i j[\mathrm{~A}] . \\ I_{i j}^{\mathrm{Sw}, \mathrm{sqr}} & \text { Square of } I_{i j}^{\mathrm{sw}} . \\ P_{i}^{s} & \text { Active power generated at node } i[\mathrm{~kW}] . \\ P_{i j} & \text { Active power flow through branch } i j[\mathrm{~kW}] . \\ P_{i j}^{\mathrm{sw}} & \text { Active power flow through switch } i j[\mathrm{~kW}] . \\ Q_{i}^{s} & \text { Reactive power generated at node } i[\mathrm{kVAr}] . \\ Q_{i j} & \text { Reactive power flow through branch } i j[\mathrm{kVAr}] . \\ Q_{i j}^{\mathrm{sw}} & \text { Reactive power flow through switch } i j[\mathrm{kVAr}] . \\ r_{i} & \text { Percentage of load-shedding at node } i[\%] . \\ V_{i} & \text { Voltage magnitude at node } i[\mathrm{kV}] \\ V_{i}^{\mathrm{sqr}} & \text { Square of } V_{i} . \\ y & \text { Argument of function } f . \\ y^{+} & \text {Auxiliary variable used in the calculation of }|y| . \\ y^{-} & \text {Auxiliary variable used in the calculation of }|y| .\end{array}$

\section{Binary Variables}

$w_{i j} \quad$ Status of switch $i j$, where $w_{i j}=1$ if switch $i j$ is closed, or $w_{i j}=0$, otherwise.

$x_{z} \quad$ Binary variable that indicates the state of zone $z$. If $x_{z}=1$, then zone $z$ is energized; if $x_{z}=0$, then zone $z$ is de-energized.

\section{INTRODUCTION}

$\mathbf{S}$ ELF-HEALING is the capacity of electrical distribution systems to automatically restore themselves if a permanent fault occurs. Depending on the level of automation, self-healing schemes isolate permanent faults in certain zones of the grid and restore the electrical service to other zones as soon as possible and with minimal human intervention. After a permanent fault has been located, optimal restoration minimizes the number of interrupted users and guarantees that the new topology maintains the system's constraints within their limits. A truly automated self-healing scheme is only possible within a smart grid context, as remote-controlled switching devices are used to isolate faulty zones and transfer loads to alternative sources, and direct load control devices installed in specific nodes of the system, are used to de-energize nonvital loads (i.e., remote load-shedding) [1].

As shown in Fig. 1, the self-healing scheme is activated when a permanent fault has been located and identified by the protection scheme and the supervisory control and data acquisition (SCADA) system. This is, when the coordinated operations of the protective devices installed along the feeders, or the meters connected to a SCADA system, locate a faulty zone, the self-healing scheme is deployed to immediately determine the set of restoration strategies to be carried out [2]. After the permanent fault has been repaired by maintenance crews, the distribution system is returned to its original operation state and the self-healing process ends.

A self-healing scheme can follow two approaches depending on the decision maker. The first is a remote approach, which is based on the ability of the protective and switching devices to communicate and coordinate control actions among themselves. Currently, these features are incorporated into intelligent electronic devices (IEDs) that control the reclosing and switching mechanisms, or it can be programmed into existing equipment [3]. Although this remote approach is suitable for specific loads that has to be restored very quickly, such as in hospitals, if not well coordinated with the dynamics of the load and the existing protecting equipment, a totally remote self-healing scheme applied to an entire distribution network could cause nuisance tripping, constraints violations, or power quality complaints. The second approach is called centralized self-healing [4]. In this approach, all of the electrical and operative system information is gathered by the IEDs in the field and sent by the SCADA system to the control center where the self-healing scheme is installed. Then, if there is a permanent fault, the self-healing system executes a set of restorative actions. Thus, the objective of this paper is to develop a methodology based on mathematical optimization in order to efficiently determine the best restorative actions to be taken after a permanent fault is located in the system, considering the electrical and operational constraints.

Some works analyzing the optimal restoration of electrical distribution systems can be found within the specialized literature. Due to the nonlinearity and combinatorial nature of the problem, most optimization techniques have been based on heuristic or meta-heuristic algorithms. Early works provided a sequence of rules for restoring the system based on the experience of system operators [5]-[6]. More elaborate heuristics [7]-[10] considered the electrical constraints of the system and used mathematical formulations to improve the quality of the solutions and to reduce the search space. The multiobjective problem of maximizing the amount of load to be restored while minimizing the number of switching operations was considered in [11] and [12] using a heuristic algorithm. More recently, meta-heuristics [13]-[15], and fuzzy algorithms [16] have been efficiently employed to obtain quality solutions to the restoration problem; however, optimality could not be guaranteed. Over the last decade, new, interesting algorithms have been proposed. Dynamic programming is used in [17] to determine the time sequence in which each zone should be energized after a blackout. Thiébaux et al. [18] proposed a flexible mixed integer linear programming (MILP) model for solving the restoration problem, including multiple objectives and switch sequence operation, based on a dc flow model. Nguyen and Flueck [19] showed a restoration 
algorithm to be deployed in a remote self-healing scheme, and Botea et al. [20] used a systematic search strategy called $A^{*}$ for performing an efficient restoration plan based on the cost of transferring a load among feeders. Although the methodology in [20] guarantees optimality, its implementation requires a highly specialized algorithm, and it does not consider some electrical constraints like voltage deviation. New characteristics have also been added to the problem, such as distributed generation resources [21] and unbalanced load flow [22]. However, neither heuristic nor meta-heuristic algorithms guarantee the optimality of the final solution. At the same time, specialized methods, such as $\mathrm{A}^{*}$ algorithms, require a detailed implementation phase.

This paper presents a two-stage procedure based on mathematical optimization, which is used to solve the centralized self-healing scheme to restore the system once a permanent fault has been identified, considering load, and zone shedding where possible. Switching device status (open or closed) and zone status (energized or not) are represented by binary decision variables. The proposed methodology determines the system's topology that isolates the faulty zone and minimizes the number of de-energized nodes and zones by transferring the load among feeders, while maintaining the operational network constraints (i.e., voltage magnitude limits, current capacity of conductors, radial operation, and source capacity) within their limits. Service restoration will occur if and only if the new system's topology is feasible. If the demand is too high to be supplied by any of the nonfaulty feeders, the self-healing scheme will disconnect nonpriority loads by carrying out remote load-shedding where possible. The objective function minimizes the amount of de-energized load and zones, the number of switch operations, and the power losses of the final topology. The first stage of the proposed procedure uses a piecewise linearization in order to transform the original nonlinear problem into an MILP model. The MILP model obtains the binary decision variables for the self-healing scheme and guarantees optimality by using existing classical optimization tools. In the second stage, the binary decision variables found in the first stage are fixed to produce a nonlinear programming (NLP) problem that calculates the steady-state operating point of the solution's topology. A 43-node test system and a real Brazilian distribution system with 964-nodes were employed to demonstrate the accuracy and efficiency of the proposed methodology by simulating different outages for each test system. The procedure was implemented using a mathematical programming language (AMPL) [23]; the first stage solution was found via the commercial optimization solver CPLEX [24], and the second stage solution was found via the commercial solver nonlinear interior-point trust region optimizer (KNITRO) [25].

Finally, in order to avoid using heuristic, meta-heuristic, or exhaustive search algorithms, which are neither flexible nor easy to develop and modify, we propose a mathematical approach. By employing this technique, utilities engineers would spend less time programming, maintaining, and updating the self-healing software and more time analyzing and improving the results of the restorative actions.
The main contributions of this research are as follows:

1) a novel, realistic, and precise ac model for solving the centralized self-healing scheme for electrical distribution systems considering the electrical and operational constraints of the electrical distribution systems;

2) a two-stage procedure to obtain an efficient solution for the problem with the following benefits:

a) a flexible approach;

b) efficient computational behavior because of the use of commercial optimization solvers;

c) a convergence to optimality guaranteed in the first stage.

\section{Mathematical Model}

The analytical expressions used to calculate the steady-state operation of the electrical distribution systems are based on the mathematical representation used in the backward/forward sweep load flow algorithms [26]-[27]. The expressions are developed according to the following assumptions.

1) The electrical loads in the electrical distribution systems are constant active and reactive power loads at every node.

2) The system is assumed to be balanced and represented by its single-phase equivalent circuit.

3) The switches are short-length circuits with very low impedance.

The mathematical model for representing the centralized self-healing scheme in radial electrical network, considering load-shedding, can be represented as a mixed-integer NLP (MINLP) problem shown in (4)-(23). Since the current and voltage magnitudes appear as squared variables, hence, it is convenient to consider the following change in variables:

$$
\begin{aligned}
I_{i j}^{\mathrm{sqr}} & =I_{i j}^{2} \quad i j \in \Omega_{l} \\
I_{i j}^{\mathrm{sw}, \mathrm{sqr}} & =\left(I_{i j}^{\mathrm{sw}}\right)^{2} \quad i j \in \Omega_{\mathrm{sw}} \\
V_{i}^{\mathrm{sqr}} & =V_{i}^{2} \quad i \in \Omega_{b}
\end{aligned}
$$

where $I_{i j}^{\mathrm{sqr}}, I_{i j}^{\mathrm{sw}, \mathrm{sqr}}$, and $V_{i}^{\mathrm{sqr}}$ are non-negative continuous variables. Also, note that in the MINLP problem in (4)-(23), the system is divided into load zones, where each zone is a section of the system containing nodes that are radially connected and delimited by the interconnection switches

$$
\begin{aligned}
& \min \sum_{z \in \Omega_{z}} c_{z}^{R}\left(1-x_{z}\right)+\sum_{i \in \Omega_{b}} c_{i}^{\mathrm{ls}} P_{i}^{D} r_{i}+c^{\mathrm{lss}} \sum_{i j \in \Omega_{l}} R_{i j} I_{i j}^{\mathrm{sqr}} \\
& +c^{\mathrm{sw}} \sum_{i j \in \Omega_{\mathrm{sw}}:}\left(1-w_{i j}\right)+c^{\mathrm{sw}} \sum_{i j \in \Omega_{\mathrm{sw}}:} w_{i j} \\
& s_{i j}^{\text {ini }}=1 \quad s_{i j}^{\text {ini }}=0
\end{aligned}
$$

subject to

$$
\begin{gathered}
\sum_{j i \in \Omega_{l}} P_{j i}-\sum_{i j \in \Omega_{l}}\left(P_{i j}+R_{i j} I_{i j}^{\mathrm{sqr}}\right)+\sum_{j i \in \Omega_{\mathrm{sw}}} P_{j i}^{\mathrm{sw}}-\sum_{i j \in \Omega_{\mathrm{sw}}} P_{i j}^{\mathrm{sw}} \\
+P_{i}^{s}=P_{i}^{D}\left(x_{z_{i}^{b}}-r_{i}\right) \quad \forall i \in \Omega_{b} \\
\sum_{j i \in \Omega_{l}} Q_{j i}-\sum_{i j \in \Omega_{l}}\left(Q_{i j}+X_{i j} I_{i j}^{\mathrm{sqr}}\right)+\sum_{j i \in \Omega_{\mathrm{sw}}} Q_{j i}^{\mathrm{sw}}-\sum_{i j \in \Omega_{\mathrm{sw}}} Q_{i j}^{\mathrm{sw}} \\
+Q_{i}^{s}=Q_{i}^{D}\left(x_{z_{i}^{b}}-r_{i}\right) \quad \forall i \in \Omega_{b}
\end{gathered}
$$




$$
\begin{aligned}
& 0 \leq r_{i} \leq \bar{r}_{i} x_{z_{i}^{b}} \quad \forall i \in \Omega_{b} \\
& V_{i}^{\mathrm{sqr}}-2\left(R_{i j} P_{i j}+X_{i j} Q_{i j}\right)-Z_{i j}^{2} I_{i j}^{\mathrm{sqr}}-V_{j}^{\mathrm{sqr}}=0 \quad \forall i j \in \Omega_{l} \\
& V_{j}^{\mathrm{sqr}} I_{i j}^{\mathrm{sqr}}=P_{i j}^{2}+Q_{i j}^{2} \quad \forall i j \in \Omega_{l} \\
& 0 \leq I_{i j}^{\mathrm{sqr}} \leq \bar{I}_{i j}^{2} x_{z_{i j}^{l}} \quad \forall i j \in \Omega_{l} \\
& -\bar{V}^{2}\left(1-w_{i j}\right) \leq V_{i}^{\mathrm{sqr}}-V_{j}^{\mathrm{sqr}} \leq \bar{V}^{2}\left(1-w_{i j}\right) \quad \forall i j \in \Omega_{\mathrm{sw}} \\
& V_{j}^{\mathrm{sqr}} I_{i j}^{\mathrm{sw}, \mathrm{sqr}}=\left(P_{i j}^{\mathrm{sw}}\right)^{2}+\left(Q_{i j}^{\mathrm{sw}}\right)^{2} \quad \forall i j \in \Omega_{\mathrm{sw}} \\
& 0 \leq I_{i j}^{\mathrm{sw}, \mathrm{sqr}} \leq\left(\bar{I}_{i j}^{\mathrm{sw}}\right)^{2} w_{i j} \quad \forall i j \in \Omega_{\mathrm{sw}} \\
& -\bar{V} \bar{I}_{i j}^{\mathrm{sw}} w_{i j} \leq P_{i j}^{\mathrm{sw}} \leq \bar{V} \bar{I}_{i j}^{\mathrm{sw}} w_{i j} \quad \forall i j \in \Omega_{\mathrm{sw}} \\
& -\bar{V} \bar{I}_{i j}^{\mathrm{sw}} w_{i j} \leq Q_{i j}^{\mathrm{sw}} \leq \bar{V} \bar{I}_{i j}^{\mathrm{sw}} w_{i j} \quad \forall i j \in \Omega_{\mathrm{sw}} \\
& \left(P_{i}^{s}\right)^{2}+\left(Q_{i}^{s}\right)^{2} \leq \bar{S}_{i}^{2} \quad \forall i \in \Omega_{b}^{s} \\
& \underline{V}^{2} x_{z_{i}^{b}} \leq V_{i}^{\mathrm{sqr}} \leq \bar{V}^{2} x_{z_{i}^{b}} \quad \forall i \in \Omega_{b} \\
& \left|\Omega_{l}\right|+\sum_{i j \in \Omega_{\mathrm{sw}}} w_{i j}=\left|\Omega_{b}\right|-\left|\Omega_{b}^{s}\right|-\sum_{z \in \Omega_{z}}\left(1-x_{z}\right) \\
& \sum_{i j \in \Omega_{\mathrm{sw}}:} w_{i j}+\sum_{j i \in \Omega_{\mathrm{sw}}:} w_{j i} \geq x_{z} \quad \forall z \in \Omega_{z} \\
& z_{i}^{b}=z \quad z_{i}^{b}=z \\
& w_{i j} \leq x_{z_{i}^{b}} \quad \forall i j \in \Omega_{\mathrm{sw}} \\
& w_{i j} \leq x_{z_{j}^{b}} \quad \forall i j \in \Omega_{\mathrm{sw}} \\
& w_{i j} \in\{0,1\} \quad \forall i j \in \Omega_{\mathrm{sw}} \\
& x_{z} \in\{0,1\} \quad \forall z \in \Omega_{z} \text {. }
\end{aligned}
$$

The objective function in (4) is assembled in five parts: 1) minimizes the cost of the de-energized zones; 2) minimizes the cost of the load-shedding in the nodes; 3) minimizes the cost of the active power losses; and 4) and 5) minimize the cost of the total switch operations after reconfiguring the system. In the case of nonremote-controlled switches, the cost of switch operations can be modified as follows.

1) The switch operation cost can be specified for every switch, by using $c_{i j}^{\mathrm{sw}}$. Thus, nonremote-controlled switches can have higher operational costs depending on the value of $c_{i j}^{\mathrm{sw}}$, for each switch $i j$.

2) If any switch cannot be operated during the self-healing scheme, then the following constraint can be added to the model: $w_{i j}=S_{i j}^{\text {ini }}$.

Constraints (5) and (6) represent the active and reactive power flow balance for each node and guarantee connectivity along the feeders. Active and reactive power flows through the switching devices are also considered in (5) and (6), respectively. Constraint (7) limits the percentage of loadshedding allowed in each node if the node's zone $z$ is energized $\left(x_{z_{i}^{b}}=1\right)$; otherwise, the load-shedding is set to zero. Constraint (8) calculates the voltage drop for radial electrical distribution systems as a function of the active and reactive power flows, the current magnitudes, and the circuit branch parameters. Constraint (9) calculates the current magnitude throughout the circuit branches. Constraint (10) limits the current magnitude throughout the branches; if the branch's zone is energized $\left(x_{z_{i j}^{l}}=1\right)$, then the maximum current magnitude must be guaranteed; otherwise, all branches within the de-energized zone do not conduct current. Constraint (11) controls the voltage magnitude between switchable nodes; if switch $i j$ is closed $\left(w_{i j}=1\right)$, then the voltage magnitudes of the nodes are equal; otherwise, if $w_{i j}=0$, both nodal voltages can vary freely within their operational constraints. Constraint (12) is equivalent to (9), but for switching devices. Constraints (13)-(15) define the limits for the current magnitude, active power, and reactive power flow through switching devices if they are closed; otherwise, all magnitudes are equal to zero.

Constraint (16) represents the source nodes generation capacity according to the parameter $\bar{S}_{i}$ established for every substation or feeder source node. Voltage magnitude limits are guaranteed by (17); note that if the node's zone is de-energized $\left(x_{z_{i}^{b}}=0\right)$, then the voltage magnitudes are set to zero.

Together, constraint (18) and the active and reactive power flow balance in constraints (5) and (6) establish the necessary and sufficient conditions for producing a final radial topology as demonstrated in [28]. Constraints (19)-(21) are auxiliary constraints for modeling the de-energized zones. Note that a zone is energized $\left(x_{z}=1\right)$ if any of the switches around the zone are closed; otherwise, the zone will be de-energized. A de-energized zone is represented as a unique, isolated radial portion of the grid in which all electrical variables are set to zero. Constraints (22) and (23) define the binary nature of variables $w_{i j}$ and $x_{z}$.

Equations (4)-(8), (10)-(11), (13)-(15), and (17)-(23) are linear expressions, while (9), (12), and (16) are nonlinear due to the multiplication between current and voltage squared magnitudes and the square of the active and reactive power flows. Thus, the model (4)-(23) is a MINLP problem that is combinatorial, nonconvex, and difficult to solve even with modern optimization solvers.

\section{Proposed Methodology}

A two-stage procedure is proposed for solving the MINLP model in (4)-(23). The first stage solves an MILP problem that is an approximation of (4)-(23) in order to determine the binary decision variables for the self-healing scheme, i.e., the switching device status $\left(w_{i j}\right)$ and energized zones $\left(x_{z}\right)$. The second stage solves a NLP problem obtained from the evaluation of the binary decision variables calculated at the first stage, into (4)-(21) model. The second stage corrects the steady-state operating point of the new system's topology and optimizes the continuous load-shedding in the nodes. The methodology is summarized in the flow chart of Fig. 2.

\section{A. Approximated MILP Model}

The MILP model used in the first stage requires some simplification and linearization methods of the MINLP problem in (4)-(23). In order to linearize the product between $V_{j}^{\mathrm{sqr}} I_{i j}^{\mathrm{sqr}}$ and $V_{j}^{\mathrm{sqr}} I_{i j}^{\mathrm{sW}, \mathrm{sqr}}$ in (9) and (12), voltage magnitude is considered to be nominal $\left(V^{\text {nom }}\right)$, then the expressions in (24) and (25) are obtained

$$
\begin{aligned}
V_{j}^{\mathrm{sqr}} I_{i j}^{\mathrm{sqr}} & \approx\left(V^{\mathrm{nom}}\right)^{2} I_{i j}^{\mathrm{sqr}} \quad \forall i j \in \Omega_{l} \\
V_{j}^{\mathrm{sqr}} I_{i j}^{\mathrm{sw}, \mathrm{sqr}} & \approx\left(V^{\mathrm{nom}}\right)^{2} I_{i j}^{\mathrm{sw}, \mathrm{sqr}} \quad \forall i j \in \Omega_{\mathrm{sw}} .
\end{aligned}
$$




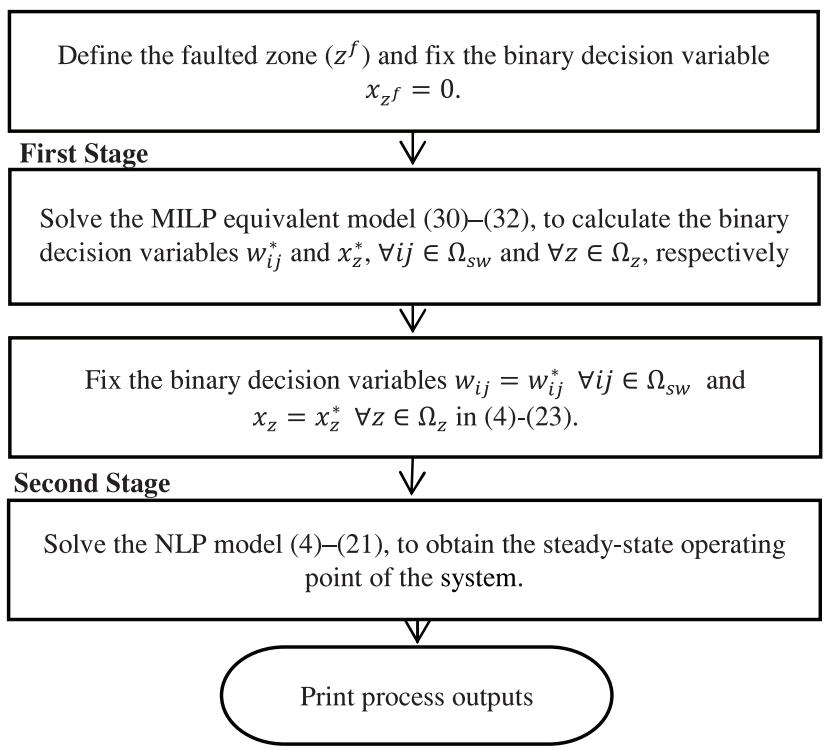

Fig. 2. Flow chart of the proposed methodology.

The simplifications of (24) and (25) have a relatively low approximation error due to the narrow voltage magnitude interval $\left[\underline{V}^{2}, \bar{V}^{2}\right]$ normally considered in the distribution system operation.

The quadratic terms $P_{i j}^{2}, Q_{i j}^{2},\left(P_{i j}^{\mathrm{sw}}\right)^{2}$, and $\left(Q_{i j}^{\mathrm{sw}}\right)^{2}$ in (9) and (12) are linearized using a piecewise linear approximation function formulated by (26) and (27). This is a standard procedure also used in [29]-[31] for other electrical system optimization problems

$$
\begin{gathered}
P_{i j}^{2}+Q_{i j}^{2} \approx f\left(P_{i j}, \bar{V} \bar{I}_{i j}, \Lambda\right)+f\left(Q_{i j}, \bar{V} \bar{I}_{i j}, \Lambda\right) \quad \forall i j \in \Omega_{l} \\
\left(P_{i j}^{\mathrm{sw}}\right)^{2}+\left(Q_{i j}^{\mathrm{sw}}\right)^{2} \approx f\left(P_{i j}^{\mathrm{sw}}, \bar{V} \bar{I}_{i j}^{\mathrm{sw}}, \Lambda\right)+f\left(Q_{i j}^{\mathrm{sw}}, \bar{V} \bar{I}_{i j}^{\mathrm{sw}}, \Lambda\right) \\
\forall i j \in \Omega_{\mathrm{sw}} .
\end{gathered}
$$

The piecewise linear approximation function $f(y, \bar{y}, \Lambda)$ is defined as follows:

$$
\begin{aligned}
& f(y, \bar{y}, \Lambda)=\sum_{\lambda=1}^{\Lambda} \phi_{y, \lambda} \Delta_{y, \lambda} \\
& y=y^{+}-y^{-} \\
& y^{+}+y^{-}=\sum_{\lambda=1}^{\Lambda} \Delta_{y, \lambda} \\
& 0 \leq \Delta_{y, \lambda} \leq \bar{y} / \Lambda \quad \forall \lambda=1, \ldots, \Lambda \\
& \phi_{y, \lambda}=(2 \lambda-1) \bar{y} / \Lambda \quad \forall \lambda=1, \ldots, \Lambda \\
& y^{+}, y^{-} \geq 0 .
\end{aligned}
$$

Fig. 3 shows how the piecewise linear function $f(y, \bar{y}, \Lambda)$ approximates the quadratic curve. Equation (28a) approximates the square value of a given variable $y$ by using the variables $\Delta_{y, \lambda}$ in order to discretize the absolute value of $y$, represented as $y^{+}+y^{-}$in the interval $[0, \bar{y}]$. The parameter $\phi_{y, \lambda}$ represents the slope of the $\lambda$ th line segments of the linearization method and is used to compute the contribution of $\Delta_{y, \lambda}$ for each step of the discretization. The bound $\bar{y} / \Lambda$ in (28d) and (28e) represents the relative magnitude of the $\Lambda$

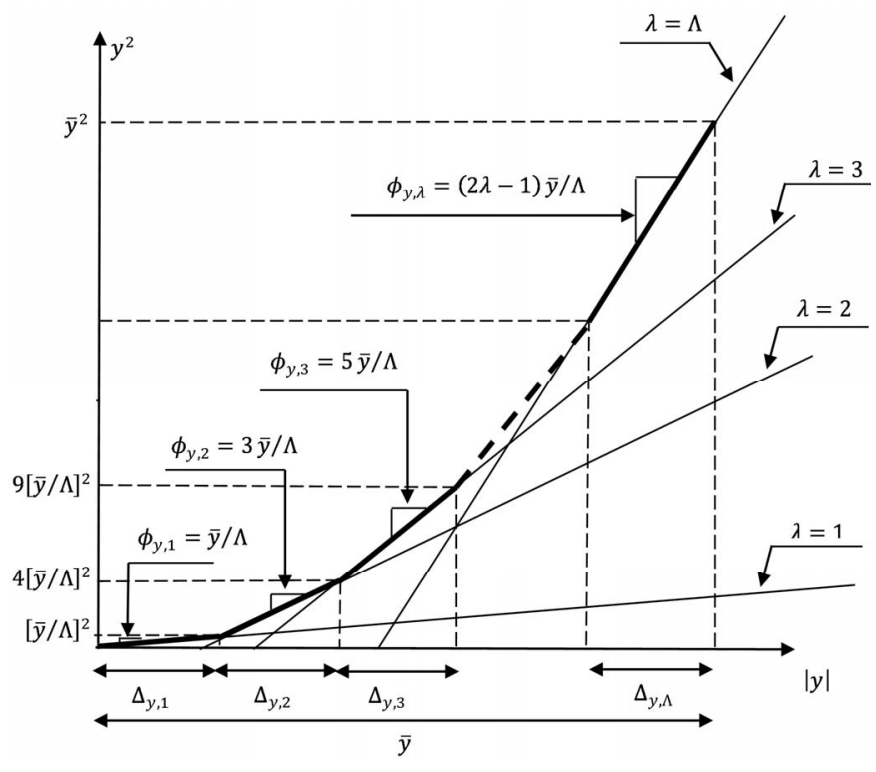

Fig. 3. Piecewise linear approximation function.

discretized segments (pieces) utilized in the linearization method. $\Delta_{y, \lambda}$ is a set of continuous variables that denotes the magnitude of the discretized segments (pieces), the sum of which is equal to $|y|$ according to (28c). $y^{+}$and $y^{-}$are non-negative variables used to model $|y|$. The parameter $\bar{y}$ represents the maximum value of $y$. Bigger values of $\Lambda$ improve the fitting of the piecewise linear approximation function. Notice that (28a) is a set of linear equations.

Constraint (16) represents the maximum substation capacity. Using the function $f(y, \bar{y}, \Lambda)$, it is possible to obtain a piecewise linear approximation of (16)

$$
f\left(P_{i}^{s}, \bar{S}_{i}, \Lambda\right)+f\left(Q_{i}^{s}, \bar{S}_{i}, \Lambda\right) \leq \bar{S}_{i}^{2} \quad \forall i \in \Omega_{b}^{s}
$$

Finally, the MILP model is given by

$$
\min (4)
$$

Subject to: (5)-(8), (10), (11), (13)-(15), (17)-(23), (29)

$$
\begin{gathered}
\left(V^{\mathrm{nom}}\right)^{2} I_{i j}^{\mathrm{sqr}}=f\left(P_{i j}, \bar{V} \bar{I}_{i j}, \Lambda\right)+f\left(Q_{i j}, \bar{V} \bar{I}_{i j}, \Lambda\right) \\
\forall i j \in \Omega_{l} \\
\left(V^{\mathrm{nom}}\right)^{2} I_{i j}^{\mathrm{sw}, \mathrm{sqr}}=f\left(P_{i j}^{\mathrm{sw}}, \bar{V} \bar{I}_{i j}^{\mathrm{sw}}, \Lambda\right)+f\left(Q_{i j}^{\mathrm{sw}}, \bar{V} \bar{I}_{i j}^{\mathrm{sw}}, \Lambda\right) \\
\forall i j \in \Omega_{\mathrm{sw}} .
\end{gathered}
$$

Note that constraint (31) replaces (9); (32) replaces (12) and (29) replaces (16). The number of continuous variables is increased by the linearization; meanwhile, the number of binary variables ( $w_{i j}$ and $x_{z}$ ) remains unchanged. The following strategies can be used to improve the first stage approximation.

1) Increase the number of linear piecewise discretization $\Lambda$ used in the function $f(y, \bar{y}, \Lambda)$.

2) Improve the voltage magnitude simplification established by (24) and (25), e.g., by using an initial load flow analysis. 


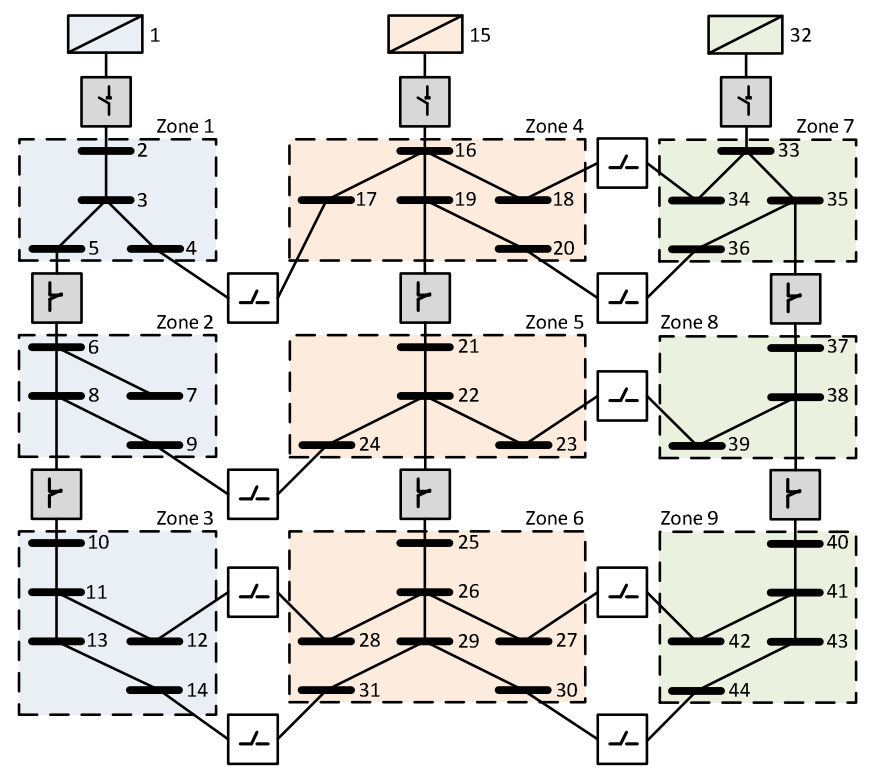

Fig. 4. Forty four-node test system—initial topology.

\section{Tests And Results}

A 44-node test system and a real-Brazilian distribution system of 964-nodes were used to demonstrate the performance of the proposed methodology. The MILP problem in (30)-(32) and the NLP problem in (4)-(21) were implemented via the mathematical programming language AMPL [23], and solutions were obtained using the commercial solvers CPLEX [24] and KNITRO [25], respectively, with default options and a maximum gap of $1 \%$ as the optimality criterion for the MILP, on a workstation with an Intel Core i5-4570 processor. For all of the piecewise linearization functions the number of discretized segments chosen was $\Lambda=20$.

\section{A. 44-Node Test System}

The 44-node test system in Fig. 4 is a radial distribution system with three radial independent feeders (blue, red, and green), 44 nodes, 38 branches, 18 switching devices, and nine load zones. The voltages limits are as follows: $V^{\text {nom }}=$ $7.967 \mathrm{kV}, \underline{V}=0.95 V^{\text {nom }}$, and $\bar{V}=V^{\text {nom }}$. Table I shows the bus data of the 44-node test system; nodes that have not been included in Table I are interconnection nodes without load (i.e., $P^{D}=Q^{D}=\bar{r}=0$ ). For simplicity, all branch parameters are considered equal, with $R_{i j}=0.9 \Omega, X_{i j}=0.9 \Omega, \bar{I}_{i j}=200 \mathrm{~A}$ $\forall i j \in \Omega_{l}$, and $\bar{I}_{i j}^{\mathrm{sw}}=1000 \mathrm{~A} \forall i j \in \Omega_{\mathrm{sw}}$.

The weights used in the objective function are established according to a hierarchical system, which determines the importance of the operations (from most to least important) needed to restore the system. Therefore, in order of importance, the costs of the restorative operations in the objective function are designed as follows: 1) to energize the maximum number of zones by applying a cost of $c_{z}^{R}=5 \mathrm{U} \$ / \mathrm{kW} \forall z \in \Omega_{z}$; 2) to meet each node's demand by applying a cost of $c_{i}^{\text {ls }}=1$ $\mathrm{U} \$ / \mathrm{kW} \forall i \in \Omega_{b}$;3) to reduce the number of switch operations by applying a cost of $c^{\mathrm{sw}}=0.2 \mathrm{U} \$$ (all switches are considered equally remote-controlled); and 4) to reduce the active power losses in the branches by applying a cost of
TABLE I

Bus DATA For THE 44-NOde TEST SysteM*

\begin{tabular}{cccccc}
\hline $\begin{array}{c}\text { Node } \\
{[i]}\end{array}$ & $\begin{array}{c}P_{i}^{D} \\
{[\mathrm{~kW}]}\end{array}$ & $\begin{array}{c}Q_{i}^{D} \\
{[\mathrm{kVAr}]}\end{array}$ & $\begin{array}{c}S_{i}^{S} \\
{[\mathrm{kVA}]}\end{array}$ & $\begin{array}{c}\bar{r}_{i} \\
{[\mathrm{p} . \mathrm{u} .]}\end{array}$ & $z_{i}^{b}$ \\
\hline 1 & 0 & 0 & 900 & 0 & 0 \\
3 & 100 & 20 & 0 & 0.5 & 1 \\
6 & 100 & 20 & 0 & 0.5 & 2 \\
9 & 100 & 20 & 0 & 0.5 & 2 \\
11 & 100 & 20 & 0 & 0.5 & 3 \\
13 & 100 & 20 & 0 & 0.5 & 3 \\
15 & 0 & 0 & 900 & 0 & 0 \\
16 & 100 & 20 & 0 & 0.5 & 4 \\
22 & 100 & 20 & 0 & 0.5 & 5 \\
26 & 100 & 20 & 0 & 0.5 & 6 \\
29 & 100 & 20 & 0 & 0.5 & 6 \\
32 & 0 & 0 & 900 & 0 & 0 \\
33 & 100 & 20 & 0 & 0.5 & 7 \\
38 & 200 & 40 & 0 & 0.5 & 8 \\
41 & 200 & 40 & 0 & 0.5 & 9 \\
43 & 200 & 40 & 0 & 0.5 & 9 \\
\hline
\end{tabular}

* Nodes not included in Table 1 are interconnection buses with no demand.

TABLE II

SOURCE OPERATIONS FOR THE 44-NODE SySTEM: INITIAL TOPOLOGY

\begin{tabular}{ccccc}
\hline $\begin{array}{c}\text { Node } \\
{[i]}\end{array}$ & $\begin{array}{c}P_{i}^{S} \\
{[\mathrm{~kW}]}\end{array}$ & $\begin{array}{c}Q_{i}^{S} \\
{[\mathrm{kVAr}]}\end{array}$ & $\begin{array}{c}S_{i}^{S} \\
{[\mathrm{kVA}]}\end{array}$ & $\begin{array}{c}\bar{S}_{i} \\
{[\mathrm{kVA}]}\end{array}$ \\
\hline 1 & 508.63 & 108.63 & 520.10 & 900.00 \\
15 & 403.49 & 83.49 & 412.03 & 900.00 \\
32 & 714.35 & 154.35 & 730.84 & 900.00 \\
\hline
\end{tabular}

$c^{\text {lss }}=0.01 \mathrm{U} \$ / \mathrm{kW}$. Fig. 4 shows the initial topology of the 44-node test system. Open switching devices are represented as white-colored boxes, and closed switching devices are represented as gray-colored boxes. The topology for the 44-node test system is initially radial, and each feeder is identified using a unique color for each zone.

As shown in Fig. 4, the initial operating point of the system has $26.5 \mathrm{~kW}$ active power losses. The minimum voltage magnitude obtained is 0.9683 p.u. at node 44 . All current magnitudes throughout the branches and switches are within their limits. Source operations are summarized in Table II.

1) Case 1 (Fault in Zone 7 With Available Load-Shedding): A fault was simulated in zone $7\left(z^{f}=7\right)$. The proposed methodology isolated the faulty zone by opening the switches between nodes 32 and 33, and 35 and 37. It also shed $34.8 \%$ of the load at node 43 (approximately $69.61 \mathrm{~kW}$ and $13.92 \mathrm{kVAr}$ ) and, as summarized in Table III, it transferred the unattended demand (due to the feeder 3 outage) by opening the switch between nodes 22 and 25, and closing the switches between nodes 12 and 28, and 23 and 39. The restored topology shown in Fig. 5 has $45.8 \mathrm{~kW}$ total active power losses. The minimum voltage magnitude is 0.9500 p.u., at node 44 . The current flow magnitudes throughout the branches and switches are within their operative limits. Source operations are shown in Table IV. Note that the proposed methodology only disconnected the zone 7 in order to isolate the permanent fault. Total execution time was $14.6 \mathrm{~s}$.

2) Case 2 (Fault in Zone 7 Without Load-Shedding): In case 2, the same permanent fault in zone 7 was considered, 
TABLE III

SUMMARY OF THE SWITCH OPERATIONS FOR THE RESTORED TOPOLOGY IN CASE 1

\begin{tabular}{cccccccc}
\hline $\begin{array}{c}\text { To } \\
{[i]}\end{array}$ & $\begin{array}{c}\text { From } \\
{[j]}\end{array}$ & $\begin{array}{c}\text { Initial } \\
\text { state }\end{array}$ & $\begin{array}{c}\text { Final } \\
\text { state }\end{array}$ & $\begin{array}{c}P_{i j}^{\text {SW }} \\
{[\mathrm{kW}]}\end{array}$ & $\begin{array}{c}Q_{i j}^{\mathrm{SW}} \\
{[\mathrm{kVAr}]}\end{array}$ & $\begin{array}{c}I_{i j}^{\mathrm{SW}} \\
{[\mathrm{A}]}\end{array}$ & $\begin{array}{c}\bar{I}_{i j}^{\mathrm{SW}} \\
{[\mathrm{A}]}\end{array}$ \\
\hline 12 & 28 & Open & Closed & 200.81 & 40.81 & 26.87 & 1000 \\
22 & 25 & Closed & Open & 0.00 & 0.00 & 0.00 & 1000 \\
23 & 39 & Open & Closed & 537.0 & 112.69 & 71.17 & 1000 \\
32 & 33 & Closed & Open & 0.00 & 0.00 & 0.00 & 1000 \\
35 & 37 & Closed & Open & 0.00 & 0.00 & 0.00 & 1000 \\
\hline
\end{tabular}

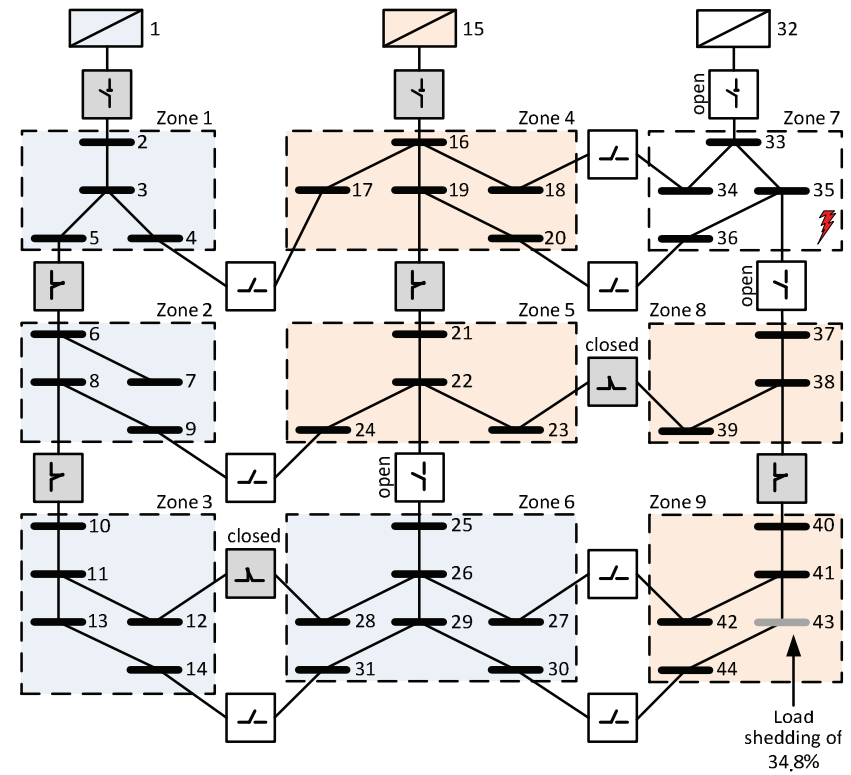

Fig. 5. Restored topology of the 44-node system-case 1.

TABLE IV

SOURCE Operations For the Restored Topology In CASE 1

\begin{tabular}{ccccc}
\hline $\begin{array}{c}\text { Node } \\
{[i]}\end{array}$ & $\begin{array}{c}P_{i}^{S} \\
{[\mathrm{~kW}]}\end{array}$ & $\begin{array}{c}Q_{i}^{S} \\
{[\mathrm{kVAr}]}\end{array}$ & $\begin{array}{c}S_{i}^{S} \\
{[\mathrm{kVA}]}\end{array}$ & $\begin{array}{c}\bar{S}_{i} \\
{[\mathrm{kVA}]}\end{array}$ \\
\hline 1 & 721.88 & 161.88 & 739.81 & 900.00 \\
15 & 754.34 & 170.03 & 773.27 & 900.00 \\
32 & 0.00 & 0.00 & 0.00 & 900.00 \\
\hline
\end{tabular}

but this time without load-shedding capacity at any node $\left(r_{i}=0, \forall i \in \Omega_{b}\right)$. The proposed methodology isolated the faulty zone 7 as well as the zone 9 by opening the switches located between nodes 32 and 33 , nodes 35 and 37 , and nodes 38 and 40 . In this case, it was necessary to isolate the zone 9 in order to avoid voltage magnitude limit violations. The proposed methodology transferred the unattended demand (due to the feeder 3 outage), to the feeder 2 by closing the switch located between nodes 23 and 39, as summarized in Table V. The restored topology depicted in Fig. 6 has $18.3 \mathrm{~kW}$ total active power losses. Minimum voltage magnitude is 0.9738 p.u., at node 14 . The current flow magnitudes throughout the branches and switches are within their operative constraints. Source operations are shown in Table VI. Both zones 7 and 9 were disconnected, which increases the amount of de-energized demand of the selfhealing scheme. In this case, the total amount of load-shedding was $400 \mathrm{~kW}$ and $80 \mathrm{kVAr}$. Total execution time was $13.1 \mathrm{~s}$.
TABLE V

SUMMARY OF THE SWITCH OPERATIONS FOR THE RESTORED TOPOLOGY IN CASE 2

\begin{tabular}{|c|c|c|c|c|c|c|c|}
\hline $\begin{array}{l}\text { To } \\
{[i]}\end{array}$ & $\begin{array}{c}\text { From } \\
{[j]}\end{array}$ & $\begin{array}{c}\text { Initial } \\
\text { state }\end{array}$ & $\begin{array}{l}\text { Final } \\
\text { state }\end{array}$ & $\begin{array}{c}P_{i j}^{S W} \\
{[\mathrm{~kW}]}\end{array}$ & $\begin{array}{c}Q_{i j}^{S W} \\
{[\mathrm{kVAr}]}\end{array}$ & $\begin{array}{l}I_{i j}^{S W} \\
{[\mathrm{~A}]}\end{array}$ & $\begin{array}{l}\bar{I}_{i j}^{S W} \\
{[\mathrm{~A}]}\end{array}$ \\
\hline 23 & 39 & Open & Closed & 200.62 & 40.62 & 26.24 & 1000 \\
\hline 32 & 33 & Closed & Open & 0.00 & 0.00 & 0.00 & 1000 \\
\hline 35 & 37 & Closed & Open & 0.00 & 0.00 & 0.00 & 1000 \\
\hline 38 & 40 & Closed & Open & 0.00 & 0.00 & 0.00 & 1000 \\
\hline
\end{tabular}

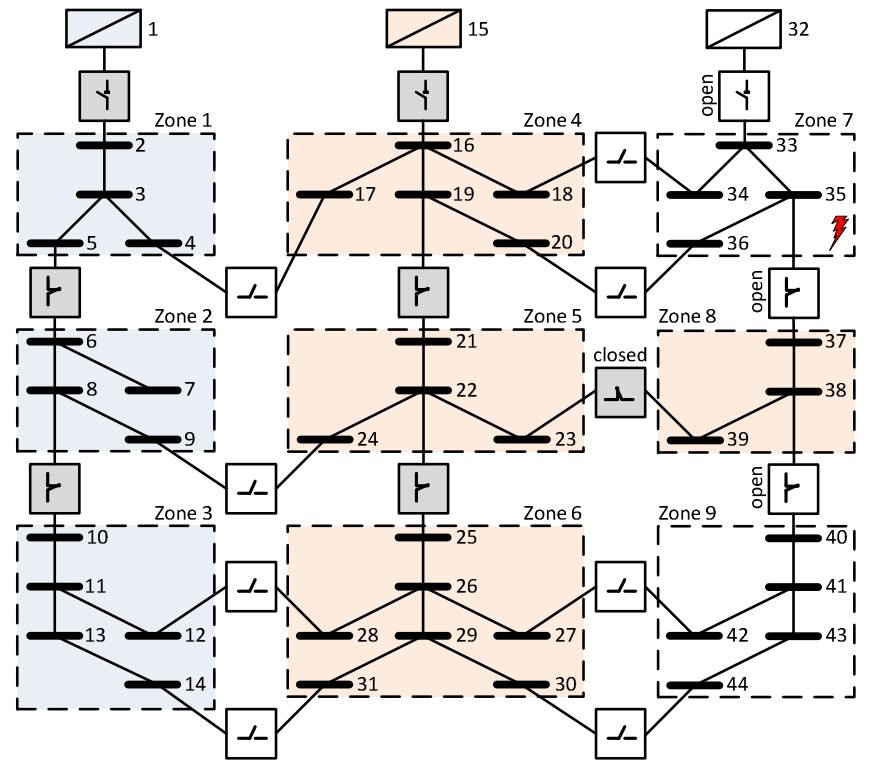

Fig. 6. Restored topology of the 44-node system—case 2 .

TABLE VI

Source Operations for the Restored Topology in CASE 2

\begin{tabular}{ccccc}
\hline $\begin{array}{c}\text { Node } \\
{[i]}\end{array}$ & $\begin{array}{c}P_{i}^{S} \\
{[\mathrm{~kW}]}\end{array}$ & $\begin{array}{c}Q_{i}^{S} \\
{[\mathrm{kVAr}]}\end{array}$ & $\begin{array}{c}S_{i}^{S} \\
{[\mathrm{kVA}]}\end{array}$ & $\begin{array}{c}\bar{S}_{i} \\
{[\mathrm{kVA}]}\end{array}$ \\
\hline 1 & 508.63 & 108.63 & 520.10 & 900.00 \\
15 & 609.72 & 129.72 & 623.37 & 900.00 \\
32 & 0.00 & 0.00 & 0.00 & 900.00 \\
\hline
\end{tabular}

3) Case 3 (Fault in Zone 7 Without Load-Shedding Capacity and With DG Operation): Distributed generation (DG) operation can be easily considered by modifying the power balance constraints in (5) and (6) in order to add a constant power injection at each node with connected DG. Thus, constraint (5) is replaced by (33) and constraint (6) is replaced by (34) in the proposed MILP model without losing the convexity of the original (30)-(32) model. Parameters $P_{i}^{\mathrm{DG}}$ and $Q_{i}^{\text {DG }}$ represent the amount of active and reactive power generated at each node $i \in \Omega_{b}$, respectively

$$
\begin{aligned}
\sum_{j i \in \Omega_{l}} P_{j i}- & \sum_{i j \in \Omega_{l}}\left(P_{i j}+R_{i j} I_{i j}^{\mathrm{sqr}}\right)+\sum_{j i \in \Omega_{s w}} P_{j i}^{\mathrm{sw}}-\sum_{i j \in \Omega_{s w}} P_{i j}^{\mathrm{sw}}+P_{i}^{s} \\
& =\left(P_{i}^{D}-P_{i}^{\mathrm{DG}}\right)\left(x_{z_{i}^{b}}-r_{i}\right) \quad \forall i \in \Omega_{b} \\
\sum_{j i \in \Omega_{l}} Q_{j i}- & \sum_{i j \in \Omega_{l}}\left(Q_{i j}+X_{i j} I_{i j}^{\mathrm{sqr}}\right)+\sum_{j i \in \Omega_{\mathrm{sw}}} Q_{j i}^{\mathrm{sw}}-\sum_{i j \in \Omega_{s w}} Q_{i j}^{\mathrm{sw}}+Q_{i}^{s} \\
= & \left(Q_{i}^{D}-Q_{i}^{\mathrm{DG}}\right)\left(x_{z_{i}^{b}}-r_{i}\right) \quad \forall i \in \Omega_{b} .
\end{aligned}
$$


TABLE VII

SUMMARY OF THE SWITCH OPERATIONS FOR THE RESTORED TOPOLOGY IN CASE 3

\begin{tabular}{cccccccc}
\hline $\begin{array}{c}\text { To } \\
{[i]}\end{array}$ & $\begin{array}{c}\text { From } \\
{[j]}\end{array}$ & $\begin{array}{c}\text { Initial } \\
\text { state }\end{array}$ & $\begin{array}{c}\text { Final } \\
\text { state }\end{array}$ & $\begin{array}{c}P_{i j}^{S W} \\
{[\mathrm{~kW}]}\end{array}$ & $\begin{array}{c}Q_{i j}^{S W} \\
{[\mathrm{kVAr}]}\end{array}$ & $\begin{array}{c}I_{i j}^{S W} \\
{[\mathrm{~A}]}\end{array}$ & $\begin{array}{c}\bar{I}_{i j}^{S W} \\
{[\mathrm{~A}]}\end{array}$ \\
\hline 12 & 28 & Open & Closed & 200.81 & 40.81 & 26.87 & 1000 \\
22 & 25 & Closed & Open & 0.00 & 0.00 & 0.00 & 1000 \\
23 & 39 & Open & Closed & 455.43 & 125.43 & 61.37 & 1000 \\
32 & 33 & Closed & Open & 0.00 & 0.00 & 0.00 & 1000 \\
35 & 37 & Closed & Open & 0.00 & 0.00 & 0.00 & 1000 \\
\hline
\end{tabular}

TABLE VIII

SOURCE Operations For THE RESTORED TOPOLOGY IN CASE 3

\begin{tabular}{ccccc}
\hline $\begin{array}{c}\text { Node } \\
{[i]}\end{array}$ & $\begin{array}{c}P_{i}^{S} \\
{[\mathrm{~kW}]}\end{array}$ & $\begin{array}{c}Q_{i}^{S} \\
{[\mathrm{kVAr}]}\end{array}$ & $\begin{array}{c}S_{i}^{S} \\
{[\mathrm{kVA}]}\end{array}$ & $\begin{array}{c}\bar{S}_{i} \\
{[\mathrm{kVA}]}\end{array}$ \\
\hline 1 & 721.88 & 161.88 & 739.81 & 900.00 \\
15 & 668.67 & 178.67 & 692.13 & 900.00 \\
32 & 0.00 & 0.00 & 0.00 & 900.00 \\
\hline
\end{tabular}

Consider a DG connected at node 42 (zone 9) of the 44-node test system, modeled by a constant injection of $150 \mathrm{~kW}$. Parameter $P_{i}^{\mathrm{DG}}$ is equal to $150 \mathrm{~kW}$ if $i=42$, zero otherwise, and $Q_{i}^{\mathrm{DG}}=0$ for all $i \in \Omega_{b}$. Computing a permanent fault in zone 7 , the DG-considered self-healing model produced the same topology of Fig. 5, but this time the DG operation at node 42 prevented any load-shedding in the system. Switch operations are summarized in Table VII. The minimum voltage magnitude is 0.9518 p.u., at node 30 . Source operations are shown in Table VIII. Compared with the results obtained in case 1, the DG resources improved the amount of energized load after restoration, reduced the power generation of the main sources, and enhanced the voltage profile of the system. Finally, (33) and (34) guaranteed that any DG resource within a de-energized zone would be disconnected and its islanded operation would not be allowed due to the radiality constraint.

\section{B. Real-Brazilian Distribution System With 964-Nodes}

Fig. 7 shows all of the interconnected zones in a realBrazilian distribution system that was used to demonstrate the flexibility and efficiency of the proposed methodology when applied to real cases. The electrical distribution system is radial and has three independent feeders (red, blue, and green), 964 nodes, 855 branches, 136 switches, and 106 load zones. The voltages magnitude limits are as follows: $V^{\text {nom }}=13.8 \mathrm{kV}$, $\underline{V}=0.93 V^{\mathrm{nom}}$, and $\bar{V}=V^{\text {nom }}$. The weights in the objective function are identical to those employed in the 44-node test system.

The steady-state operating point of the initial topology in Fig. 7 has $14.8 \mathrm{~kW}$ total active power losses. Current magnitudes throughout the branches and switches are within their operative constraints. The initial source operations are summarized in Table IX. Neither circuit branches nor nodes have been included; only load zones and interconnection switches are displayed in Fig. 7 for convenience. Open switching devices are represented by discontinuous lines.

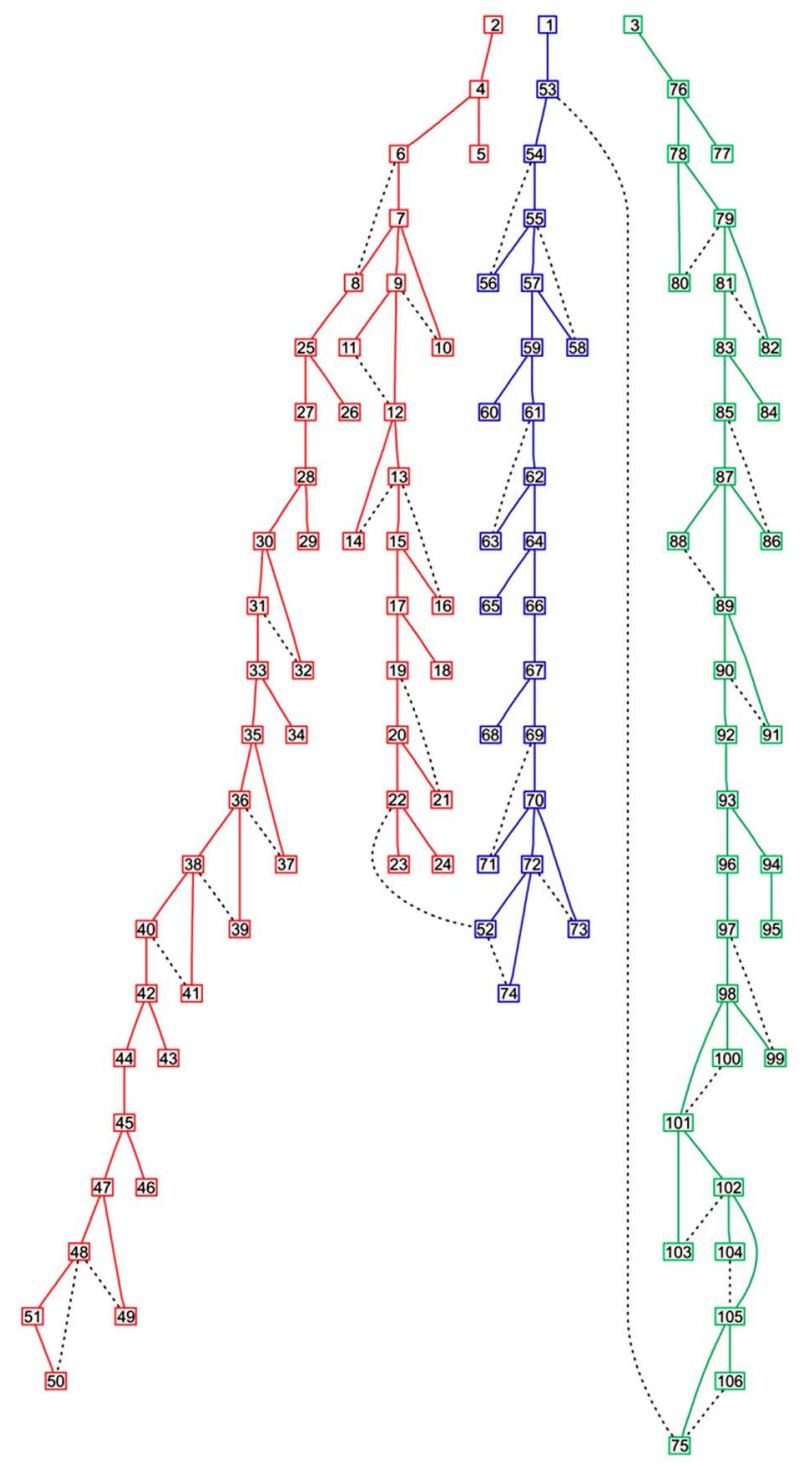

Fig. 7. Real-distribution system: initial topology.

TABLE IX

SOURCE OPERATIONS FOR THE REAL-DISTRIBUTION SYSTEM: INITIAL TOPOLOGY

\begin{tabular}{lcccc}
\hline $\begin{array}{c}\text { Source } \\
{\left[z_{i}^{b}\right]}\end{array}$ & $\begin{array}{c}P_{i}^{S} \\
{[\mathrm{~kW}]}\end{array}$ & $\begin{array}{c}Q_{i}^{S} \\
{[\mathrm{kVAr}]}\end{array}$ & $\begin{array}{c}S_{i}^{S} \\
{[\mathrm{kVA}]}\end{array}$ & $\begin{array}{c}\bar{S}_{i} \\
{[\mathrm{kVA}]}\end{array}$ \\
\hline 1 (blue) & 762.60 & 573.37 & 954.10 & 10000 \\
2 (red) & 1422.61 & 1071.90 & 1781.23 & 10000 \\
3 (green) & 793.66 & 596.00 & 992.53 & 10000 \\
\hline
\end{tabular}

Case 1: A permanent fault was simulated at zone 9 $\left(z^{f}=9\right)$, which was energized by the switch located between zone 7 and 9 . The proposed methodology isolated the faulty zone 9 by opening the switches between zones 7 and 9 , 9 and 11, and 9 and 12. The proposed methodology transferred the unattended demand from the red feeder to the blue feeder by closing the switches between zones 11 and 12 , and 22 and 52, as outlined in Table X.

Furthermore, the solution suggested a load-shedding of $21.72 \%$ at node 107 in zone 11 . This load-shedding was 
TABLE $X$

Switch Operations for the Restoration of Real System. Case 1

\begin{tabular}{cccccccc}
\hline $\begin{array}{c}\text { To } \\
{\left[z_{i}^{b}\right]}\end{array}$ & $\begin{array}{c}\text { From } \\
{\left[z_{j}^{b}\right]}\end{array}$ & $\begin{array}{c}\text { Initial } \\
\text { state }\end{array}$ & $\begin{array}{c}\text { Final } \\
\text { state }\end{array}$ & $\begin{array}{c}P_{i j}^{S W} \\
{[\mathrm{~kW}]}\end{array}$ & $\begin{array}{c}Q_{i j}^{S W}[\mathrm{kVAr}] \\
{\left[\begin{array}{c}\text { Closed } \\
7\end{array}\right.}\end{array}$ & $\begin{array}{c}I_{i j}^{S W} \\
{[\mathrm{~A}]}\end{array}$ & $\begin{array}{c}\bar{I}_{i j}^{s w} \\
{[\mathrm{~A}]}\end{array}$ \\
\hline 9 & 11 & Open & 0.00 & 0.00 & 0.00 & 1000 \\
9 & 12 & Closed & Open & 0.00 & 0.00 & 0.00 & 1000 \\
11 & 12 & Open & Open & 0.00 & 0.00 & 0.00 & 1000 \\
22 & 52 & Open & Closed & -118.45 & -88.84 & -18.76 & 1000 \\
& & & & & & &
\end{tabular}

TABLE XI

LOAD-SHEDDING FOR THE RESTORATION OF THE REAL-SYSTEM IN CASES 1 AND 2

\begin{tabular}{cccc}
\hline Case & \multicolumn{3}{c}{ Load Shedding } \\
\cline { 2 - 4 } & Zone & {$[\mathrm{kVA}]$} & {$[\%]$} \\
\hline 1 & 11 & 36.2 & 21.72 \\
2 & 14 & 50.0 & 100.0 \\
\hline
\end{tabular}

TABLE XII

SOURCE OPERATIONS FOR THE RESTORATION of THE REAL System. CASE 1

\begin{tabular}{ccccc}
\hline $\begin{array}{c}\text { Source } \\
{\left[z_{i}^{b}\right]}\end{array}$ & $\begin{array}{c}P_{i}^{S} \\
{[\mathrm{~kW}]}\end{array}$ & $\begin{array}{c}Q_{i}^{S} \\
{[\mathrm{kVAr}]}\end{array}$ & $\begin{array}{c}S_{i}^{S} \\
{[\mathrm{kVA}]}\end{array}$ & $\begin{array}{c}\bar{S}_{i} \\
{[\mathrm{kVA}]}\end{array}$ \\
\hline 1 (blue) & 1272.55 & 958.93 & 1593.40 & 10000 \\
2 (red) & 884.14 & 665.34 & 1106.52 & 10000 \\
3 (green) & 793.66 & 596.00 & 992.53 & 10000 \\
\hline
\end{tabular}

TABLE XIII

SWITCH OPERATIONS FOR THE RESTORATION OF THE REAL SYSTEM. CASE 2

\begin{tabular}{|c|c|c|c|c|c|c|c|}
\hline $\begin{array}{c}\text { To } \\
{\left[z_{i}^{b}\right]}\end{array}$ & $\begin{array}{c}\text { From } \\
{\left[z_{j}^{b}\right]}\end{array}$ & $\begin{array}{c}\text { Initial } \\
\text { state }\end{array}$ & $\begin{array}{c}\text { Final } \\
\text { state }\end{array}$ & $\begin{array}{c}P_{i j}^{S W} \\
{[\mathrm{~kW}]}\end{array}$ & $\begin{array}{c}Q_{i j}^{S W} \\
{[\mathrm{kVAr}]}\end{array}$ & $\begin{array}{l}I_{i j}^{S W} \\
{[\mathrm{~A}]}\end{array}$ & $\begin{array}{l}\bar{I}_{i j}^{s w} \\
{[\mathrm{~A}]}\end{array}$ \\
\hline 7 & 9 & Closed & Open & 0.00 & 0.00 & 0.00 & 1000 \\
\hline 9 & 11 & Closed & Open & 0.00 & 0.00 & 0.00 & 1000 \\
\hline 9 & 12 & Closed & Open & 0.00 & 0.00 & 0.00 & 1000 \\
\hline 11 & 12 & Open & Closed & -133.33 & -100.00 & -21.11 & 1000 \\
\hline 12 & 14 & Closed & Open & 0.00 & 0.00 & 0.00 & 1000 \\
\hline 22 & 52 & Open & Closed & -493.47 & -370.17 & -78.10 & 1000 \\
\hline
\end{tabular}

necessary to avoid exceeding the current limit capacity of the circuits in zone 54 (blue feeder) which have a common current capacity of $200 \mathrm{~A}$. This capacity would not be enough to support the total current of the new configuration once zones 11-24 have been transferred to the blue feeder. Table XI consolidates the load-shedding actions for the restoration of the real system in case 1 .

The solution's topology for case 1 is radial with $15.2 \mathrm{~kW}$ total active power losses. The currents throughout the branches and switches are within their operative limits. The source operations are shown in Table XII. Total execution time was $243.8 \mathrm{~s}$, which proves that the two-stage procedure is computationally efficient even for large systems.

Case 2: Consider, once again, a permanent fault in zone 9, but this time without load-shedding capacity. The proposed methodology isolated the faulty zone 9 and transferred the unattended demand by closing the switches between the zones 11 and 12, and 22 and 52. Moreover, the solution suggested de-energizing the zone 14 by opening the switch
TABLE XIV

SOURCE OPERATIONS FOR THE RESTORATION of the REAL System. CASE 2

\begin{tabular}{ccccc}
\hline $\begin{array}{c}\text { Source } \\
{\left[z_{i}^{b}\right]}\end{array}$ & $\begin{array}{c}P_{i}^{S} \\
{[\mathrm{~kW}]}\end{array}$ & $\begin{array}{c}Q_{i}^{S} \\
{[\mathrm{kVAr}]}\end{array}$ & $\begin{array}{c}S_{i}^{S} \\
{[\mathrm{kVA}]}\end{array}$ & $\begin{array}{c}\bar{S}_{i} \\
{[\mathrm{kVA}]}\end{array}$ \\
\hline 1 (blue) & 1261.35 & 950.43 & 1579.34 & 10000 \\
2 (red) & 884.14 & 665.34 & 1106.52 & 10000 \\
3 (green) & 793.66 & 596.00 & 992.53 & 10000 \\
\hline
\end{tabular}

between zones 12 and 14 (see Table XIII). Total execution time was $388.4 \mathrm{~s}$. In this case, $50 \mathrm{kVA}$ was de-energized to ensure feasibility. The switch and source operations for case 2 are shown in Tables XIII and XIV, respectively.

1) Execution Time Improvement: In order to improve the total execution time of the proposed methodology, the following strategies are proposed.

1) Improve the computational resources or the processing capacity of the computer being used to solve the problem.

2) Increase the maximum convergence gap of the CPLEX at the first stage.

3) Establish a maximum execution time at the first stage, using the time-stopping criterion of the CPLEX.

4) Eliminate the second stage.

Finally, consider that strategies 2 to 4 are tradeoff between the quality of the final solution and the execution time of the proposed methodology.

\section{CONClusion}

This paper proposes a two-stage procedure for the centralized self-healing scheme to restore electrical distribution systems after a sustained fault in any zone, considering both load and zone shedding. The first stage uses a piecewise linearization function to turn the original problem into an MILP model. The solution of an MILP model guarantees optimality by using existing classical optimization tools. At the second stage, the decision binary variables are fixed to produce a NLP problem that determines the steady-state operating point of the solution topology obtained in the first stage. The proposed methodology finds feasible and high-quality solutions for establishing the system's operation. The solution isolates the faulty zone and minimizes the number of de-energized nodes and zones by transferring load among feeders, maintaining the network operational constraints within their limits, and disconnecting nonpriority loads through load and zone shedding, if necessary.

A 43-node test system and a real Brazilian distribution system with 964-nodes were used to test and verify the proposed methodology. For all cases, the methodology isolated the faulty zones and proposed a feasible system topology to minimize the de-energized load and operate under healthy conditions. The load-shedding decreased the unattended zones and improved the flexibility of the self-healing scheme providing an efficient response to the fault. The results show that the proposed self-healing methodology is efficient and robust during the restoration of electrical distribution systems in the context of smart grids. 


\section{REFERENCES}

[1] J. R. Aguero, "Applying self-healing schemes to modern power distribution systems," in Proc. IEEE Power Energy Soc. Gen. Meeting, San Diego, CA, USA, 2012, pp. 1-4.

[2] M. K. Khedkar and G. M. Dhole, A Textbook of Electric Power Distribution Automation. New Delhi, India: Laxmi, 2010.

[3] Y. Oualmakran, J. Melendez, and S. Herraiz, "Self-healing for smart grids: Problem formulation and considerations," in Proc. 3rd IEEE PES Int. Conf. Exhibit. Innov. Smart Grid Technol., Berlin, Germany, 2012, pp. 1-6.

[4] A. Zidan and E. F. El-Saadany, "A cooperative multiagent framework for self-healing mechanisms in distribution systems," IEEE Trans. Smart Grid, vol. 3, no. 3, pp. 1525-1539, Sep. 2012.

[5] C.-C. Liu, L. Seung-Jae, and S. S. Venkata, "An expert system operational aid for restoration and loss reduction of distribution systems," IEEE Trans. Power Syst., vol. 3, no. 2, pp. 619-626, May 1988.

[6] Y.-Y. Hsu et al., "Distribution system service restoration using a heuristic search approach," IEEE Trans. Power Del., vol. 7, no. 2, pp. 734-740, Apr. 1992.

[7] K. Aoki, K. Nara, M. Itoh, T. Satoh, and H. Kuwabara, "A new algorithm for service restoration in distribution systems," IEEE Trans. Power Del., vol. 4, no. 3, pp. 1832-1839, Jul. 1989.

[8] A. L. Morelato and A. Monticelli, "Heuristic search approach to distribution system restoration," IEEE Trans. Power Del., vol. 4, no. 4, pp. 2235-2241, Oct. 1989.

[9] N. D. R. Sarma, S. Ghosh, K. S. P. Rao, and M. Srinivas, "Real time service restoration in distribution networks-A practical approach," IEEE Trans. Power Del., vol. 9, no. 4, pp. 2064-2070, Oct. 1994.

[10] N. D. R. Sarma, V. C. Prasad, K. S. P. Rao, and V. Sankar, "A new network reconfiguration technique for service restoration in distribution networks," IEEE Trans. Power Del., vol. 9, no. 4, pp. 1936-1942, Oct. 1994.

[11] K. N. Miu, C. Hsiao-Dong, Y. Bentao, and G. Darling, "Fast service restoration for large-scale distribution systems with priority customers and constraints," IEEE Trans. Power Syst., vol. 13, no. 3, pp. 789-795, Aug. 1998.

[12] D. Shirmohammadi, "Service restoration in distribution networks via network reconfiguration," IEEE Trans. Power Del., vol. 7, no. 2, pp. 952-958, Apr. 1992.

[13] Y. Fukuyama and C. Hsaio-Dong, "A parallel genetic algorithm for service restoration in electric power distribution systems," in Proc. IEEE 4th Int. Joint Conf. Fuzzy Syst. 2nd Int. Fuzzy Eng. Symp., Yokohama, Japan, 1995, pp. 275-282.

[14] S. Toune, H. Fudo, T. Genji, Y. Fukuyama, and Y. Nakanishi, "Comparative study of modern heuristic algorithms to service restoration in distribution systems," IEEE Trans. Power Del., vol. 17, no. 1, pp. 173-181, Jan. 2002.

[15] Y. Kumar, B. Das, and J. Sharma, "Multiobjective, multiconstraint service restoration of electric power distribution system with priority customers," IEEE Trans. Power Del., vol. 23, no. 1, pp. 261-270, Jan. 2008.

[16] C.-M. Huang, "Multiobjective service restoration of distribution systems using fuzzy cause-effect networks," IEEE Trans. Power Syst., vol. 18, no. 2, pp. 867-874, May 2003.

[17] R. Perez-Guerrero, G. T. Heydt, N. J. Jack, B. K. Keel, and A. R. Castelhano, "Optimal restoration of distribution systems using dynamic programming," IEEE Trans. Power Del., vol. 23, no. 3, pp. 1589-1596, Jul. 2008.

[18] S. Thiébaux, C. Coffrin, H. Hijazi, and J. Slaney, "Planning with MIP for supply restoration in power distribution systems," in Proc. 23rd Int. Joint Conf. Artif. Netw., Beijing, China, 2013, pp. 2900-2907.

[19] C. P. Nguyen and A. J. Flueck, "Agent based restoration with distributed energy storage support in smart grids," IEEE Trans. Smart Grid, vol. 3, no. 2, pp. 1029-1038, Jun. 2012.

[20] A. Botea, J. Rintanen, and D. Banerjee, "Optimal reconfiguration for supply restoration with informed A* search," IEEE Trans. Smart Grid, vol. 3, no. 2, pp. 583-593, Jun. 2012.

[21] L. Dapeng, W. Shouxiang, Z. Jie, and Z. Yishu, "A self-healing reconfiguration technique for smart distribution networks with DGs," in Proc. Int. Conf. Elect. Control Eng. (ICECE), Yichang, China, 2011, pp. 4318-4321.

[22] A. Zidan and E. F. El-Saadany, "Service restoration in balanced and unbalanced distribution systems with high DG penetration," in Proc. IEEE Power Energy Soc. Gen. Meeting, San Diego, CA, USA, 2011, pp. $1-8$.
[23] R. Fourer, D. M. E. Gay, and B. W. Kernighan, AMPL: A Modeling Language for Mathematical Programming, 2nd ed. Pacific Grove, CA, USA: Brooks/Cole-Thomson Learning, 2003.

[24] CPLEX Optimization Subroutine Library Guide and Reference, Version 11.0, CPLEX Division, ILOG Inc., Incline Village, NV, USA, 2008.

[25] R. H. Byrd, J. E. Nocedal, and R. A. Waltz, "KNITRO: An integrated package for nonlinear optimization," in Large-Scale Nonlinear Optimization, vol. 83. New York, NY, USA: Springer, pp. 35-59, 2006.

[26] R. G. Cespedes, "New method for the analysis of distribution networks," IEEE Trans. Power Del., vol. 5, no. 1, pp. 391-396, Jan. 1990.

[27] D. Shirmohammadi, H. W. Hong, A. Semlyen, and G. X. Luo, "A compensation based power flow method for weakly meshed distribution and transmission networks," IEEE Trans. Power Syst., vol. 3, no. 2, pp. 753-762, May 1988.

[28] M. Lavorato, J. F. Franco, M. J. Rider, and R. Romero, "Imposing radiality constraints in distribution system optimization problems," IEEE Trans. Power Syst., vol. 27, no. 1, pp. 172-180, Feb. 2012.

[29] J. Franco, M. J. Rider, M. Lavorato, and R. Romero, "Optimal conductor size selection and reconductoring in radial distribution systems using a mixed-integer LP approach," IEEE Trans. Power Syst., vol. 28, no. 1, pp. 10-20, Feb. 2013.

[30] N. Alguacil, A. L. Motto, and A. J. Conejo, "Transmission expansion planning: A mixed-integer LP approach," IEEE Trans. Power Syst., vol. 18, no. 3, pp. 1070-1077, Aug. 2003.

[31] Z. Hui, V. Vittal, G. T. Heydt, and J. Quintero, "A mixed-integer linear programming approach for multi-stage security-constrained transmission expansion planning," IEEE Trans. Power Syst., vol. 27, no. 2, pp. 1125-1133, May 2012.

Patricia L. Cavalcante received the B.Sc. degree in computer engineering from Pontifícia Universidade Católica de Goiás, Goiânia, Brazil, in 2008, and the M.Sc. degree in electrical engineering from the University of Campinas, Campinas, Brazil, in 2010, where she is currently pursuing the Ph.D. degree in electrical engineering.

She is currently a Project Coordinator with the Centro de Pesquisa e Desenvolvimento em Telecomunicações, Campinas. Her current research interests include development of methodologies for automation, operation, planning, and control of electrical power systems.

Juan Camilo López received the double B.Sc. degrees in electronical engineering and electrical engineering from the Universidad Nacional de Colombia, Bogotá, Colombia, in 2011 and 2012, respectively, and the M.Sc. degree in electrical engineering from Universidade Estadual Paulista, Ilha Solteira, Brazil, in 2015. He is currently pursuing the Ph.D. degree in electrical engineering with the Universidade Estadual de Campinas, Campinas, Brazil.

His current research interests include development of methodologies for the optimization, planning, and control of electrical power systems.

John F. Franco (S'11-M'13) received the B.Sc. and M.Sc. degrees in electrical engineering from the Universidad Tecnológica de Pereira, Pereira, Colombia, in 2004 and 2006, respectively, and the Ph.D. degree from São Paulo State University, Ilha Solteira, Brazil, in 2012, all in electrical engineering.

$\mathrm{He}$ is currently a Postdoctoral Researcher with the Facultade de Engenheria de Ilha Solteira, Universidade Estadual Paulista, Ilha Solteira, Brazil. His current research interests include development of methodologies for the optimization, planning, and control of electrical power systems. 
Marcos J. Rider (S'97-M'06) received the B.Sc. (Hons.) and P.E. degrees from the National University of Engineering, Lima, Peru, in 1999 and 2000 respectively; the M.Sc. degree from the Federal University of Maranhão, Maranhão, Brazil, in 2002; and the Ph.D. degree from the University of Campinas (UNICAMP), Campinas, Brazil, in 2006, all in electrical engineering.

He is currently a Professor with the Department of Systems and Energy, UNICAMP. His current research interests include development of methodologies for the optimization, planning, and control of electrical power systems, and applications of artificial intelligence in power systems.

Ariovaldo V. Garcia received the B.Sc., M.Sc., and Ph.D. degrees in electrical engineering from the State University of Campinas (UNICAMP), Campinas, Brazil, in 1974, 1977, and 1981, respectively.

From 1975 to 2010, he was with the Department of Electrical Energy Systems, UNICAMP, where he is currently an Independent Consultant. He has served as a Consultant for a number of organizations. His current research interests include planning and control of electrical power systems.

Marcos R. R. Malveira received the B.Sc. degree in electrical engineering from the University of Campinas, Campinas, Brazil, in 2010.

He is currently an Engineer with the Centro de Pesquisa e Desenvolvimento em Telecomunicações, Campinas. His current research interests include distribution automation, conditioning monitoring, and power systems.
Luana L. Martins received the B.Sc. degree in electrical engineering from Universidade Estadual Paulista, Bauru, Brazil, in 2011. She is currently pursuing the M.Sc. degree in electrical engineering with the University of Campinas, Campinas, Brazil.

She is an Engineer with the Centro de Pesquisa e Desenvolvimento em Telecomunicações, Campinas. Her current research interests include distribution automation, power quality, and power systems.

Luiz Carlos M. Direito received the B.Sc. degree in electrical engineering from Universidade Santa Úrsula, Rio de Janeiro, Brazil, in 1992, and the M.Sc. degree in computer from Universidade Federal Fluminense, Niterói, Brazil, in 2009.

He is currently an Automation, Meter, and Technology Manager with the Light Serviços de Eletricidade S. A., Rio de Janeiro, Brazil. 